Review

\title{
Piperine: A Savor Inducer and a Cancer Reducer
}

\author{
Meir Djaldetti *
}

Laboratory for Immunology and Hematology Research, Rabin Medical Center, Hasharon Hospital, Petah-Tiqva, the Sackler School of Medicine, Tel-Aviv University, Ramat Aviv, Israel; E-Mail: meird@clalit.org.il

* Correspondence: Meir Djaldetti; E-Mail: meird@clalit.org.il

Academic Editor: Osamu Yokosuka

OBM Hepatology and Gastroenterology

2021, volume 5, issue 3

doi:10.21926/obm.hg.2103061
Received: July 26, 2021

Accepted: September 03, 2021

Published: September 15, 2021

\begin{abstract}
Spices have been used for many decades, and although new and improved culinary spices have been developed, black pepper (Piper nigrum) continues to retain its distinguished title as the "King of spices" due to its particular pungent taste. An alkaloid called piperine is the main component in black pepper that, besides generating the well-known taste, imparts well-documented immunomodulatory, anti-inflammatory, antimicrobial, antioxidant, and even anti-cancer properties; these properties have led to rigorous research on black pepper. Studies conducted on cancer cell lines and in animal models with tumors revealed that piperine might influence tumor development and metastasis via various pathways, some of which are quite common for most types of malignant processes, while others are associated with a specific type of cancer. In this review, we summarized the effect of piperine on various types of cancer and the mechanism by which it acts as a carcinopreventive agent.
\end{abstract}

\section{Keywords}

Piperine; black pepper; cancer; spices conditions of the Creative Commons by Attribution License, which permits unrestricted use, distribution, and reproduction in any medium or format, provided the original work is correctly cited. 


\section{Introduction}

The history of spices and their introduction to the western countries is closely linked to ancient explorers and their journeys to new lands. These explorers carried new spices to improve the taste and flavor of food and laid the foundation of modern cuisine. The high value of spices in olden times influenced trade throughout Europe [1]. Our ancestors noted the beneficial effects of curative plants and included a significant number of spices in the armamentarium of traditional folk medicine. They believed that spices had healing effects since they emerged from paradise and spread throughout the world [2]. There is a huge variety of spices available currently, but the most important one that is commonly used by all is black pepper (Piper nigrum). Due to its widespread usage, it is also called the "King of spices" [3,4]. Gradually, the pharmacological properties of black pepper, such as its antimicrobial, antioxidant, and anti-inflammatory activities, became more evident and encouraged researchers to explain the mechanism of these functions, a process thoroughly reviewed by Takoree et al. [5]. Piperine, the principal alkaloid in black pepper, was determined as a highly bioactive component [5]. In addition to the above-mentioned pharmacological activities, piperine facilitates the absorptive and therapeutic capabilities of conventional drugs, when used together [6]. Therefore, efforts have been made to extract greater quantities of pure piperine from its source. Li et al. [7, 8] developed a multistage extraction method to obtain alkaloids from plants that express antibacterial, antioxidant, and anti-cancer activities. Using this method, 99\% pure piperine was extracted [9]. Studies have shown that black pepper possesses a potential anti-cancer effect against several types of malignant cell lines that develop a dose-dependent inhibition of tumor cell proliferation, COX enzymes, nuclear transcription factor kappa- $\beta$, and lipid peroxidation [10,11]. The anti-cancer potential of piperine has been the subject of several studies and reviews [12-14]. Considering the close relationship between chronic inflammation and cancer development, piperine can stimulate the immunomodulatory activities of mononuclear cells by producing anti-inflammatory cytokines, and inhibit pro-inflammatory activities, thus exerting a pronounced anti-cancer effect [15-17]. Piperine can restrain or even prevent cancer development by multiple mechanisms, either common to all types of malignant cells, such as antiproliferative, antioxidant, and pro-apoptotic activities [18], or biological processes strongly associated with a specific type of cancer. Liu et al. [11] reported that black pepper extracts exert a dose-dependent suppression of human tumor cell proliferation by inhibiting TNF-induced NF-k $\beta$ activity (nuclear factor kappa promoter of B cells). Rats with nitrosomethylurea-induced mammary tumorigenesis that were fed piperine extracts showed marked suppression of tumor progression, linked with the inhibition of the production of certain cytokines and Th2 regulatory (Treg) cells, and the promotion of the function of Th1 helper cells [19]. In experiments with HT-1080 cells (a fibrosarcoma cell line), it was found that piperine affected tumor migration by reducing the level of matrix metalloproteinase-9 (MMP-9) and NF-k $\beta$, a factor that monitors DNA transcription and cytokine production [14]. A detailed review of the antimutagenic potential of piperine and its main mechanism of controlling carcinogenesis was published by Stojanovic-Radic et al. [15]. Interestingly, the doses of piperine applied in the different experiments differed according to the type of cancer, the setup of the experiment, and the goal to be achieved [17, 20, 21] (Table 1). Since cancers of the digestive tract and the breast are the most common malignancies affecting humans, the majority of investigations on the antimutagenic effect of piperine have been conducted on these types of cells. This review aimed 
to provide an overview of the recent studies regarding the potential carcinopreventive effect of piperine in various malignancies.

Table 1 Piperine doses used in different experiments to obtain anti-cancer effects.

\begin{tabular}{|c|c|c|}
\hline $\begin{array}{l}\text { In vitro studies } \\
\text { Type of cancer cells }\end{array}$ & Dosage & Reference \\
\hline $\begin{array}{l}\text { KB cells-oral squamous cell } \\
\text { carcinoma }\end{array}$ & $25-300 \mu \mathrm{M}$ & [16] \\
\hline DLD-1 cells, colon carcinoma & $100-200 \mu \mathrm{M}$ & {$[21]$} \\
\hline $\begin{array}{l}\text { HCT-116, SW480, DLD-1 cells, } \\
\text { colorectal carcinoma }\end{array}$ & $100-200 \mu \mathrm{M}$ & {$[22]$} \\
\hline 4T1 cells, murine breast carcinoma & $35-280 \mathrm{mMol} / \mathrm{L}$ & [23] \\
\hline $\begin{array}{l}\text { MCF-7 cells, human breast } \\
\text { carcinoma }\end{array}$ & $20-30 \mu \mathrm{M}$ & [24] \\
\hline $\begin{array}{l}\text { MDA-MB-231 breast adeno ca, A- } \\
\text { 549-lung adeno ca, } \mathrm{HepG}_{2} \\
\text { hepatocellular ca }\end{array}$ & $\begin{array}{l}\text { 238, } 198,214 \mu \mathrm{M} \text {, respectively, to } \\
\text { achieve } \mathrm{IC}_{50}\end{array}$ & {$[25]$} \\
\hline $\begin{array}{l}\text { LNCaP, PC-3-prostate carcinoma } \\
\text { cells }\end{array}$ & $\begin{array}{l}39.91,49.45 \text {, respectively, to } \\
\text { achieve } I C_{50}\end{array}$ & [26] \\
\hline $\begin{array}{l}\text { EAC - Ehrlich ascites carcinoma } \\
\text { cells }\end{array}$ & $250 \mathrm{mg} / \mathrm{kg}$ & [17] \\
\hline \multicolumn{3}{|l|}{ In vivo studies } \\
\hline Human volunteers & $20 \mathrm{mg} / \mathrm{kg}$ & {$[20]$} \\
\hline Mice sarcoma 180 & 50 and $100 \mathrm{mg} / \mathrm{kg}$ day for 7 days & [27] \\
\hline Albino mice lung carcinoma & $50 \mathrm{mg} / \mathrm{kg}$ day for 16 weeks & {$[28,29]$} \\
\hline
\end{tabular}

\section{Piperine and Cancers of the Gastrointestinal Tract}

Oral malignancies are relatively rare and are mainly observed in chronic alcohol and tobacco consumers. Exposure of cells from a human oral squamous carcinoma line to piperine was followed by significantly reduced cell viability and increased cell death with a tendency of cell cycle arrest at the G2/M phase. Additionally, caspase-3 activation and reactive oxygen species (ROS) production were stimulated [22]. In a study on gastric adenocarcinoma, the addition of piperine to cells exposed to Helicobacter pylori, a bacterium that is known to be a carcinogen, was shown to cause a dose-dependent inhibition of the adhesion of the bacteria to the malignant cells. This was due to the ability of piperine to suppress the motility genes of the microorganism [30]. In another study with human gastric carcinoma cells (SNU-16), piperine dose-dependently inhibited cell proliferation and stimulated the apoptosis of cancer cells. Moreover, piperine diminished the tumor size when administered to tumor-bearing mice. The authors of that study concluded that this effect was due to the inhibition of PI3/Akt (Phosphoinositide 3-kinases/protein kinase B), a signaling pathway involved in the cell cycle, proliferation, and cell lifespan [31]. Studies on the effect of piperine on gastrointestinal tumors have been conducted on colorectal cancer, probably because this is one of the most common malignancies in humans [32, 33]. Similar to the effect of 
piperine on gastric cancer cells, the proliferation of HT-29 human colon cancer cells was also inhibited by piperine through cell cycle arrest at the G1 phase and an increase in apoptosis [34]. Even low doses of piperine $(100-200 \mu \mathrm{M})$ inhibited the proliferation of DLD-1 human colon cancer cells at $48 \mathrm{~h}$ and $71 \mathrm{~h}$. This suggests that the continuous administration of low doses of piperine may prevent colon cancer by inhibiting cancer cell proliferation [21]. Piperine increased the sensitivity of HT-29 colon cancer cells to gamma-irradiation by activating caspase-3 and cleaving poly (ADP-ribose) polymerase-1, factors that are linked with the enhanced apoptosis and decreased proliferation of the malignant cells [35]. Other colorectal cancer cell lines, such as HCT116, SW489, and DLD-1, showed significantly decreased cell migration, proliferation, and viability under the effect of piperine, whereas control, non-malignant cell lines were unaffected. According to the authors, piperine induced these alterations on cancer cells by inhibiting the Wnt/B-catenin signal transduction pathway [36]. Wnt signaling pathways include a group of proteins that transmit signals to cancer cells and are strongly associated with the development of colorectal cancer [37]. Rehman et al. [33] treated Wistar rats bearing dimethylhydrazine-induced colon cancer with piperine and observed a marked restoration of the damage induced by the carcinogen. Piperine decreased the level of carcinoembryonic antigen (CEA), as well as the level of other biomarkers linked with the early stages of colon cancer. Moreover, the production of the inflammatory cytokines TNF $\alpha$, IL-1 $\beta$, and IL-6, as well as that of the reactive oxygen species (ROS), decreased. Piperine displays an anti-cancer activity by stimulating the cross-talk between the nuclear erythroid 2-related factor 2 (Nrf-2) that upregulates antioxidant responses and NF-k $\beta$, a factor that is activated during cancer development and promotes malignant transformation. Experiments on rats with dimethylhydrazine-generated colon cancer fed with black pepper showed a decreased number of tumors in the colon and an intact lipid metabolism compared to the number of colon tumors and the lipid metabolism in the controls [32]. Chemoprevention depends on the self-renewal capacity of cancer stem cells, which requires three signaling pathways: Wnt/ $\beta$-catenin, Hedgehog, and Notch. Piperine and other natural dietary compounds can alter the activity of these pathways, thus impairing the conventional development of cancer cells [38]. Piperine can inhibit colorectal cell migration by targeting the epithelial-to-mesenchymal transition that is regulated by the Snail protein and the signal transducer and activator of transcription 3 (STAT3) [39]. Due to the positive effect of piperine on human health, researchers wanted to find better ways to deliver the alkaloid to cancer patients. A nanoformulation of aggregated hydroxyapatite nanoparticles loaded with piperine inhibited HCT116 colon cancer cells expressed by considerable alterations of the cell membrane and impaired intercellular adhesion [23]. In another study, emulsomes containing piperine and curcumin effectively arrested HCT116 cell proliferation at the $\mathrm{G} 2 / \mathrm{M}$ phase [40]. Collectively, these studies indicate that additional research should be conducted to determine whether piperine can be used in conventional drugs for treating colorectal cancer.

\section{Piperine and Breast Cancer}

Breast cancer is a serious threat since it is one of the most frequent malignancies and is the second most common cause of death in women [41, 42]. A significant number of vitamins, dietary components, and alkaloids, including piperine, were found to prevent development and recurrence of breast cancer, which led to the conclusion that they might have antitumor 
properties and could be used for the chemoprevention of breast cancer [43]. Lai et al. [44] examined the effect of piperine on mouse 4T1 breast carcinoma cells and showed that, when applied in vitro, piperine arrested the growth of the malignant cells by inhibiting cyclin B and delaying the $\mathrm{G} 2$ mitotic phase. Additionally, piperine increased the apoptosis of cancer cells. These effects were expressed in a dose-dependent and time-dependent manner and were linked with the activation of caspase-3, a programmed cell death marker. Notably, piperine, when administered to 4T1 breast cancer-bearing mice, suppressed tumor growth and propagation. Piperine strongly inhibited cell proliferation and apoptosis in piperine-pretreated HER2overexpressing breast cancer cells and increased their sensitivity to paclitaxel [45]. In another study, when combined with piperlongumine, another natural pepper alkaloid, piperine inhibited the proliferation and increased the apoptosis of breast cancer cells by repressing the activation of STAT3, a transcription factor known to be a cancer promoter [31]. Angiogenesis, which is important for cancer progression, was found to be inhibited by piperine in chick embryos bearing breast cancer [21]. Similar to the effect of piperine in tumors of the gastrointestinal tract, breast cancer development might also be altered by piperine through the inhibition of the inflammatory response (a process strongly associated with carcinogenesis), which suppresses the production of pro-inflammatory cytokines from immune cells $[46,47]$. Breast cancer cells are non-responsive to anti-cancer drugs due to the presence of efflux transporters, including the highly expressed multidrug resistant P-glycoprotein (P-gp) on the cell membrane. After treating drug-resistant cancer cells with piperine, added either alone or in combination with capsaicin, there was a downregulation of the expression of P-gp and the breast cancer resistance protein (BCRP), which led to a decrease in the resistance of the cells to doxorubicin, thus indicating that piperine might independently be a P-gp and BCRP suppressor [38, 48]. According to Bozorgi et al. [49], decreasing apoptosis and activating several signaling pathways related to increased cell survival are key ways by which breast cancer stem cells (BCSCs) develop drug resistance. The authors suggested the use of several herbal compounds, including piperine, to target BCSCs and prevent cancer development. The combined administration of piperine with other herbal polyphenols, such as curcumin, enhanced their cytotoxicity toward BCSCs without affecting differentiated cells [50]; nanoformulations containing piperine and anti-cancer drugs were shown to intensify this effect. Experiments have shown that administering rapamycin with piperine in nanoparticles increased the bioavailability of rapamycin by 4.8 fold, compared to the bioavailability of the drug when administered alone [51]. In another study, nanoparticles encapsulated with BioPerine (a black pepper alkaloid derivate) stimulated the in vitro cytotoxicity of the MDA-MB 453 breast cancer cell line by downregulating P-gp [24]. The administration of piperine, sulforaphane, and thymoquinone in nanoformulations showed greater bioavailability and more efficient delivery when targeting breast cancer cells compared to their activity when administered alone [52]. Piperine might be useful in the treatment of triple-negative breast cancer (TNBC), known for its violent course. According to Abdelhamed et al. [53], the beneficial effect of piperine in such cases is due to its ability to enhance TRAIL (TNF-related apoptosis-inducing ligand) therapeutic modalities. Piperine could induce caspase-dependent apoptosis of TNBC cells to inhibit their growth and migration by decreasing the number of cells entering the $\mathrm{G} 2$ phase of the mitotic cycle and reducing the expression of matrix metalloproteinases. Moreover, piperine enhanced the sensitivity of TNBC cells exposed to gamma radiation [54] and exerted a synergistic effect on the antimitotic and cytotoxic activity of conventional drugs, such as paclitaxel that target TNBCs [55]. 
Piperine, with cisplatinum, augmented the apoptosis and decreased the viability of the human MCF-7 breast cancer cell line by reducing Bcl-2 anti-apoptotic regulator and increasing caspase enzymes [56]. Encapsulation of piperine in nanoparticles or liposomes boosted the synergistic effect of the anti-cancer drugs $[55,57]$. Due to the various ways by which it can interfere with breast cancer development and the new methods for its delivery, piperine could be considered for conventional cancer therapy.

\section{Piperine and Gynecological Cancers}

Cervical, endometrial, and ovarian cancers are the main gynecological malignancies, and great efforts have been made to combat them with modern therapeutic remedies. Li et al. [7-9, 58] developed nanogels that are capable of improving drug delivery to ovarian carcinoma and have great therapeutic potential. The authors demonstrated a high drug loading capacity of the nanogels. For example, doxorubicin, loaded in these nanogels, had prolonged circulation time and greater tumor uptake. Epidemiological studies revealed that some of these tumors might be affected by phytochemicals, capable of preventing their development and spread [59]. Human cervical adenocarcinoma (HeLa) cells exposed to piperine displayed growth inhibition either due to a tendency of the cells to be arrested at the G2/M phase or due to increased apoptosis, DNA fragmentation, and cell death, linked with caspase- 3 activation and the generation of reactive oxygen species [25]. Moreover, piperine suppressed the resistance of cervical cancer cells to mitomycin and potentiated their apoptosis by upregulating Bax and Bid pro-apoptotic proteins, both of which belong to the Bcl-2 family. In a mouse model, the combination of piperine and mitomycin showed a synergistic effect in preventing tumor growth, compared to the effect of the two components when administered independently [28]. Ovarian cancer is one of the most malignant gynecological tumors, and efforts have been made to introduce novel and more effective therapeutic modalities [58]. The antitumor properties of piperine were examined on a human ovarian cell carcinoma A2780 cell line, and piperine reduced the proliferation, apoptosis, and viability of cancer cells without affecting the normal ovarian cells. Piperine activated caspase which, in turn, activated several signal transduction pathways, such as MAPK (mitogen-activated protein kinase) and JNK (Jun N-terminal kinase) [29]. Piperine, independently or in combination with anti-cancer medications, was able to overcome drug resistance of human ovarian cancer cells and demonstrated an improved cytotoxic activity $[48,60]$.

\section{Piperine and Lung Cancer}

While breast cancer is the most common malignancy in women, lung cancer is the one with the highest incidence in men and is the main cause of male morbidity and mortality [26]. Smoking and alcoholism are the main factors that dictate the global distribution of lung cancer. Besides treatment with conventional chemotherapy and radiotherapy, dietary supplements can also improve the prognosis of both small and non-small cell lung cancer. The anti-cancer activity of piperine has attracted researchers to examine its effect on lung cancer cells. Lin et al. [61] have shown that piperine exerts a pronounced cytotoxic and apoptotic effect on human lung cancer A549 cells by activating caspase- 3 and caspase- 9 cascades and by inducing p53-mediated cell cycle arrest at the $\mathrm{G} 2 / \mathrm{M}$ phase. In another study, piperine was shown to alter the epithelialmesenchymal transition process by inhibition of the transmission growth factor (TGF- $\beta$ ) signaling 
pathway, which greatly increased toxicity in the A549 cells [62]. Mice with benzo(a)pyreneinduced lung cancer showed a marked increase in the amount of lipid peroxidation, protein carbonyls, nucleic acid content, and polyamine synthesis; treatment with piperine for 16 weeks caused a significant decrease in those parameters, leading to a suppression of cell proliferation and decrease in cell damage [63]. By applying the same treatment to an animal model, the authors observed that piperine also stimulated the production of detoxification enzymes and reduced DNA damage [64].

\section{Piperine and Prostate Cancer}

The antitumor activity of piperine has been tested in prostate cancer, which is a common tumor among men and related to significant mortality. Piperine was shown to affect androgendependent (22RV1 and LNCaP) and androgen-independent (PC3 and DU145) prostate cancer cells and inhibited cell proliferation, activated caspase-3, thus increasing apoptosis and reduced cell migration. The level of PSA (Prostate-Specific Antigen) in LNCaP cells was markedly reduced [65]. Treatment of LNCaP and PC-3 cells with piperine caused a concentration-dependent cell cycle arrest at the $G_{1}$ phase and apoptosis $[66,67]$. Studies have shown that piperine inhibits the migration and proliferation of prostate cancer cells by activating signaling pathways, such as mTOR (mechanistic target of rapamycin) and MMP-9 (matrix metallopeptidase-9) [68].

\section{Piperine and Other Tumors}

The preventive effect of piperine on the more common cancers prompted researchers to study its activity on other malignant processes. Studies on the effect of piperine on melanoma cells, both in vitro and in animal models, have been published. By treating B16F-10 melanoma cells (that produce copious amounts of pro-inflammatory cytokines such as IL-1 3 . IL-6, TNF $\alpha$, and GM-CSF) with piperine, Pradeep and Kuttan [27] showed that piperine significantly reduced the production of these cells. Moreover, piperine inhibited the expression of ATF-2, C-Fos, and CREB, transcription factors that are activated in skin tumors. Piperine caused a dose- and time-dependent retardation in the growth of SK MEL 28 and B16 FO melanoma cells and induced their apoptosis via cell cycle arrest at the G1 phase and activation of the checkpoint kinase 1 (Chk1), respectively [69]. Similar results were reported by other investigators [46]. Mice with lung nodules and metastases induced by B16F-10 melanoma cells, when treated with piperine, showed a remarkable decrease in the number and size of the malignant tissue and an extended survival [70]. Treatment of hepatocellular carcinoma cells (HepG2) with piperine caused increased apoptosis due to the inhibition of peroxide detoxifying catalase [71]. The effect of piperine on HOS and U2OS osteosarcoma cells was favorable. Piperine decreased cell migration by inhibiting the expression of matrix metalloproteinase MMP-2 and MMP-9 and suppressed cell proliferation by inducing cell cycle arrest at the G2/M phase; several signaling pathways were involved in this process [72]. Reduction of the viability of HOS and 143B osteosarcoma cells after treatment with piperine has been reported in other in vitro studies [73] and animal models using Sarcoma 180 cells [74]. Interestingly, the majority of research on the carcinopreventive effect of piperine has been performed in vitro or with animal models [5], although it has been reported that administration of $20 \mathrm{mg}$ of piperine to eight healthy individuals each morning for six days was well-tolerated [75].

Zadorozhna et al. [76] observed the chemopreventive activities of piperine at doses $<250 \mu \mathrm{g} / \mathrm{mL}$, 
without any cytotoxicity in normal cells. After reviewing the physiological effects of piperine, Srinivasan [77] concluded that its anti-cancer ability was not associated with genotoxicity, a view supported by others as well [78]. Based on the favorable effects of piperine mentioned in these studies, it is necessary to conduct intensive clinical research to determine whether piperine can be used as an adjuvant to anti-cancer drugs.

In conclusion, the studies presented here support the notion that piperine has anti-cancer effects that are associated with the inhibition of the proliferation and mitosis of cancer cells due to induced cell cycle arrest, mainly at the G2 phase, through the stimulation of cell apoptosis, retardation of cell migration, and prevention of metastases. Additionally, piperine is capable of abolishing the resistance of malignant cells to conventional chemotherapeutic agents, and, administered along with anti-cancer drugs, piperine has a significant synergistic effect against the development and spread of cancer [6]. Notably, its anti-cancer activities are more pronounced when it acts with other plant alkaloids, such as curcumin, and may increase the radiosensitivity of malignant cells when combined with resveratrol [79]. Based on the above-mentioned studies on the novel ways to deliver piperine to malignant cells, along with those that showed that the administration of piperine in reasonable doses did not cause any adverse effects on normal (noncancerous) cells [80], it is plausible to assume that piperine might serve as safe and efficient support to conventional anti-cancer drugs.

\section{Author Contributions}

The author did the research work of this study.

\section{Competing Interests}

The author has declared that no competing interests exist.

\section{References}

1. Prange SR. 'Measuring by the bushel': Reweighing the Indian ocean pepper trade. Hist Res. 2011; 84: 212-235.

2. Nam JK. Medieval European medicine and Asian spices. Uisahak. 2014; 23: 319-342.

3. Joshi DR, Shrestha AC, Adhikari N. A review on diversified use of the king of spices: Piper nigrum (black pepper). Int J Pharm Sci Res. 2018; 9: 4089-4101.

4. R Vasanthi H, P Parameswari R. Indian spices for healthy heart-an overview. Curr Cardiol Rev. 2010; 6: 274-279.

5. Takooree H, Aumeeruddy MZ, Rengasamy KR, Venugopala KN, Jeewon R, Zengin G, et al. A systematic review on black pepper (Piper nigrum L.): From folk uses to pharmacological applications. Crit Rev Food Sci Nutr. 2019; 59: S210-S243.

6. Bakshi H, Nagpal M, Singh M, Dhingra GA, Aggarwal G. Propitious profile of peppery piperine. Curr Mol Pharmacol. 2020. Doi: 10.2174/1874467213666200722152636.

7. Li H, Wu X, Li X, Cao X, Li Y, Cao H, et al. Multistage extraction of star anise and black pepper derivatives for antibacterial, antioxidant, and anticancer activity. Front Chem. 2021; 9: 660138. 
8. Li X, Li H, Zhang C, Pich A, Xing L, Shi X. Intelligent nanogels with self-adaptive responsiveness for improved tumor drug delivery and augmented chemotherapy. Bioact Mater. 2021; 6: 3473-3484.

9. Li X, Shi JR, Yang MS, Lu Y, Chen L, Cao HR. Study on the extraction, geometry structure and spectral characterization of piperine alkaloid. Guang Pu Xue Yu Guang Pu Fen Xi. 2016; 36: 2082-2088.

10. Smilkov K, Ackova DG, Cvetkovski A, Ruskovska T, Vidovic B, Atalay M. Piperine: Old spice and new nutraceutical? Curr Pharm Des. 2019; 25: 1729-1739.

11. Liu Y, Yadev VR, Aggarwal BB, Nair MG. Inhibitory effects of black pepper (Piper nigrum) extracts and compounds on human tumor cell proliferation, cyclooxygenase enzymes, lipid peroxidation and nuclear transcription factor-kappa-B. Nat Prod Commun. 2010; 5: 12531257.

12. Turrini E, Sestili P, Fimognari C. Overview of the anticancer potential of the "King of Spices" piper nigrum and its main constituent piperine. Toxins. 2020; 12: 747-780.

13. Butt MS, Pasha I, Sultan MT, Randhawa MA, Saeed F, Ahmed W. Black pepper and health claims: A comprehensive treatise. Crit Rev Food Sci Nutr. 2013; 53: 875-886.

14. Butt MS, Naz A, Sultan MT, Qayyum MM. Anti-oncogenic perspectives of spices/herbs: A comprehensive review. EXCLI J. 2013; 12: 1043-1065.

15. Stojanović-Radić Z, Pejčić M, Dimitrijević M, Aleksić A, V Anil Kumar N, Salehi B, et al. Piperinea major principle of black pepper: A review of its bioactivity and studies. Appl Sci. 2019; 9: 4270-4299.

16. Djaldetti M. Piperine-an immunomodulator an inflammation mitigator. J Clin Lab Res. 2001; 2. Doi: $10.31579 / 2768-0487 / 027$.

17. Sunila ES, Kuttan G. Immunomodulatory and antitumor activity of Piper longum Linn. and piperine. J Ethnopharmacol. 2004; 90: 339-346.

18. Ranjan A, Fofaria NM, Kim SH, Srivastava SK. Modulation of signal transduction pathways by natural compounds in cancer. Chin J Nat Med. 2015; 13: 730-742.

19. Saetang J, Tedasen A, Sangkhathat S, Sangkaew N, Dokduang S, Prompat N, et al. Low piperine fractional piper nigrum extract enhanced the antitumor immunity via regulating the Th1/Th2/Treg cell subsets on NMU-induced tumorigenesis rats. Planta Med. 2021. Doi: 10.1055/a-1458-5646.

20. Shoba G, Joy D, Joseph T, Majeed M, Rajendran R, Srinivas PS. Influence of piperine on the pharmacokinetics of curcumin in animals and human volunteers. Planta Med. 1998; 64: 353356.

21. Doucette CD, Hilchie AL, Liwski R, Hoskin DW. Piperine, a dietary phytochemical, inhibits angiogenesis. J Nutr Biochem. 2013; 24: 231-239.

22. Siddiqui S, Ahamad MS, Jafri A, Afzal M, Arshad M. Piperine triggers apoptosis of human oral squamous carcinoma through cell cycle arrest and mitochondrial oxidative stress. Nutr Cancer. 2017; 69: 791-799.

23. AbouAitah K, Stefanek A, Higazy IM, Janczewska M, Swiderska-Sroda A, Chodara A, et al. Effective targeting of colon cancer cells with piperine natural anticancer prodrug using functionalized clusters of hydroxyapatite nanoparticles. Pharmaceutics. 2020; 12: 70. 
24. Pillai SC, Borah A, Jindal A, Jacob EM, Yamamoto Y, Kumar DS. BioPerine encapsulated nanoformulation for overcoming drug-resistant breast cancers. Asian J Pharm. 2020; 15: 701712.

25. Jafri A, Siddiqui S, Rais J, Ahmad MS, Kumar S, Jafar T, et al. Induction of apoptosis by piperine in human cervical adenocarcinoma via ROS mediated mitochondrial pathway and caspase-3 activation. EXCLI J. 2019; 18: 154-164.

26. Sholih MG, Perwitasari DA, Hendriani R, Sukandar H, Barliana MI, Suwantika AA, et al. Knowledge, attitudes, and practices of lung cancer risk factors in west Bandung society. J Pharm Bioallied Sci. 2019; 11: S574-S549.

27. Pradeep CR, Kuttan G. Piperine is a potent inhibitor of nuclear factor-kappaB (NF-kappaB), cFos, CREB, ATF-2 and proinflammatory cytokine gene expression in B16F-10 melanoma cells. Int Immunopharmacol. 2004; 4: 1795-1803.

28. Han SZ, Liu HX, Yang LQ, Xu Y. Piperine (PP) enhanced mitomycin-C (MMC) therapy of human cervical cancer through suppressing Bcl-2 signaling pathway via inactivating STAT3/NF-KB. Biomed Pharmacother. 2017; 96: 1403-1410.

29. Si L, Yang R, Lin R, Yang S. Piperine functions as a tumor suppressor for human ovarian tumor growth via activation of JNK/p38 MAPK-mediated intrinsic apoptotic pathway. Biosci Rep. 2018; 38: BSR20180503.

30. Tharmalingam N, Kim SH, Park M, Woo HJ, Kim HW, Yang JY, et al. Inhibitory effect of piperine on Helicobacter pylori growth and adhesion to gastric adenocarcinoma cells. Infect Agents Cancer. 2014; 9: 43.

31. Chen D, Ma Y, Guo Z, Liu L, Yang Y, Wang Y, et al. Two natural alkaloids synergistically induce apoptosis in breast cancer cells by inhibiting STAT3 activation. Molecules. 2020; 25: 216.

32. Nalini N, Manju V, Menon VP. Effect of spices on lipid metabolism in 1, 2-dimethylhydrazineinduced rat colon carcinogenesis. J Med Food. 2006; 9: 237-245.

33. Rehman MU, Rashid S, Arafah A, Qamar W, Alsaffar RM, Ahmad A, et al. Piperine regulates Nrf-2/Keap-1 signalling and exhibits anticancer effect in experimental colon carcinogenesis in wistar rats. Biology. 2020; 9: 302.

34. Yaffe PB, Power Coombs MR, Doucette CD, Walsh M, Hoskin DW. Piperine, an alkaloid from black pepper, inhibits growth of human colon cancer cells via G1 arrest and apoptosis triggered by endoplasmic reticulum stress. Mol Carcinog. 2015; 54: 1070-1085.

35. Shaheer K, Somashekarappa HM, Lakshmanan MD. Piperine sensitizes radiation-resistant cancer cells towards radiation and promotes intrinsic pathway of apoptosis. J Food Sci. 2020; 85: 4070-4079.

36. de Almeida GC, Oliveira LF, Predes D, Fokoue HH, Kuster RM, Oliveira FL, et al. Piperine suppresses the $\mathrm{Wnt} / \beta$-catenin pathway and has anti-cancer effects on colorectal cancer cells. Sci Rep. 2020; 10: 11681.

37. Zhan T, Rindtorff N, Boutros M. Wnt signaling in cancer. Oncogene. 2017; 36: 1461-173.

38. Li H, Krstin S, Wang S, Wink M. Capsaicin and piperine can overcome multidrug resistance in cancer cells to doxorubicin. Molecules. 2018; 23: 557.

39. Song L, Wang Y, Zhen Y, Li D, He X, Yang H, et al. Piperine inhibits colorectal cancer migration and invasion by regulating STAT3/Snail-mediated epithelial-mesenchymal transition. Biotechnol Lett. 2020; 42: 2049-2058. 
40. Bolat ZB, Islek Z, Demir BN, Yilmaz EN, Sahin F, Ucisik MH. Curcumin-and piperine-loaded emulsomes as combinational treatment approach enhance the anticancer activity of curcumin on HCT116 colorectal cancer model. Front Bioeng Biotechnol. 2020; 8: 50.

41. Sriwiriyajan S, Tedasen A, Lailerd N, Boonyaphiphat P, Nitiruangjarat A, Yan Deng Y, et al. Effects of piperine-free piper nigrum extract on $\mathrm{N}$-nitrosomethylurea-induced mammary tumorigenesis in rats. Cancer Prev Res. 2016; 9: 74-82.

42. Watkins EJ. Overview of breast cancer. JAAPA. 2019; 32: 13-17.

43. Mokbel K, Mokbel K. Chemoprevention of breast cancer with vitamins and micronutrients: A concise review. In Vivo. 2019; 33: 983-997.

44. Lai LH, Fu QH, Liu Y, Jiang K, Guo QM, Chen QY, et al. Piperine suppresses tumor growth and metastasis in vitro and in vivo in a 4T1 murine breast cancer model. Acta Pharmacol Sin. 2012; 33: 523-530.

45. Do MT, Kim HG, Choi JH, Khanal T, Park BH, Tran TP, et al. Antitumor efficacy of piperine in the treatment of human HER2-overexpressing breast cancer cells. Food Chem. 2013; 141: 2591-2599.

46. Yoo ES, Choo GS, Kim SH, Woo JS, Kim HJ, Park YS, et al. Antitumor and apoptosis-inducing effects of piperine on human melanoma cells. Anticancer Res. 2019; 39: 1883-1892.

47. Bessler H, Djaldetti $M$. Role of the equilibrium between colon cancer and mononuclear cells in cytokine production. Biomed Pharmacother. 2010; 64: 706-711.

48. Wojtowicz K, Sterzyńska K, Świerczewska M, Nowicki M, Zabel M, Januchowski R. Piperine targets different drug resistance mechanisms in human ovarian cancer cell lines leading to increased sensitivity to cytotoxic drugs. Int J Mol Sci. 2021; 22: 4243.

49. Bozorgi A, Khazaei S, Khademi A, Khazaei M. Natural and herbal compounds targeting breast cancer, a review based on cancer stem cells. Iran J Basic Med Sci. 2020; 23: 970-983.

50. Kakarala M, Brenner DE, Korkaya H, Cheng C, Tazi K, Ginestier C, et al. Targeting breast stem cells with the cancer preventive compounds curcumin and piperine. Breast Cancer Res Treat. 2010; 122: 777-785.

51. Katiyar SS, Muntimadugu E, Rafeeqi TA, Domb AJ, Khan W. Co-delivery of rapamycin-and piperine-loaded polymeric nanoparticles for breast cancer treatment. Drug Deliv. 2016; 23: 2608-2616.

52. Aumeeruddy MZ, Mahomoodally MF. Combating breast cancer using combination therapy with 3 phytochemicals: Piperine, sulforaphane, and thymoquinone. Cancer. 2019; 125: 16001611.

53. Abdelhamed S, Yokoyama S, Refaat A, Ogura K, Yagita H, Awale S, et al. Piperine enhances the efficacy of TRAIL-based therapy for triple-negative breast cancer cells. Anticancer Res. 2014; 34: 1893-1899.

54. Greenshields AL, Doucette CD, Sutton KM, Madera L, Annan H, Yaffe PB, et al. Piperine inhibits the growth and motility of triple-negative breast cancer cells. Cancer Lett. 2015; 357: 129-140.

55. Burande AS, Viswanadh MK, Jha A, Mehata AK, Shaik A, Agrawal N, et al. EGFR targeted paclitaxel and piperine co-loaded liposomes for the treatment of triple negative breast cancer. AAPS PharmSciTech. 2020; 21: 151. 
56. Fattah A, Morovati A, Niknam Z, Mashouri L, Asadi A, Rizi ST, et al. The synergistic combination of cisplatin and piperine induces apoptosis in MCF-7 cell line. Iran J Public Health. 2021; 50: 1037-1047.

57. Rad JG, Hoskin DW. Delivery of apoptosis-inducing piperine to triple-negative breast cancer cells via co-polymeric nanoparticles. Anticancer Res. 2020; 40: 689-694.

58. Li X, Ouyang Z, Li H, Hu C, Saha P, Xing L, et al. Dendrimer-decorated nanogels: Efficient nanocarriers for biodistribution in vivo and chemotherapy of ovarian carcinoma. Bioact Mater. 2021; 6: 3244-3253.

59. Woźniak M, Krajewski R, Makuch S, Agrawal S. Phytochemicals in gynecological cancer prevention. Int J Mol Sci. 2021; 22: 1219.

60. Qiu M, Xue C, Zhang L. Piperine alkaloid induces anticancer and apoptotic effects in cisplatin resistant ovarian carcinoma by inducing $\mathrm{G} 2 / \mathrm{M}$ phase cell cycle arrest, caspase activation and inhibition of cell migration and PI3K/Akt/GSK3 $\beta$ signalling pathway. J BUON. 2019; 24: 23162321.

61. Lin Y, Xu J, Liao H, Li L, Pan L. Piperine induces apoptosis of lung cancer A549 cells via p53dependent mitochondrial signaling pathway. Tumor Biol. 2014; 35: 3305-3310.

62. Marques da Fonseca L, Jacques da Silva LR, Santos dos Reis J, Rodrigues da Costa Santos MA, de Sousa Chaves V, Monteiro da Costa K, et al. Piperine inhibits TGF- $\beta$ signaling pathways and disrupts EMT-related events in human lung adenocarcinoma cells. Medicines. 2020; 7: 19.

63. Selvendiran K, Banu SM, Sakthisekaran D. Protective effect of piperine on benzo (a) pyreneinduced lung carcinogenesis in Swiss albino mice. Clin Chim Acta. 2004; 350: 73-78.

64. Selvendiran K, Banu SM, Sakthisekaran D. Oral supplementation of piperine leads to altered phase II enzymes and reduced DNA damage and DNA-protein cross links in Benzo (a) pyrene induced experimental lung carcinogenesis. Mol Cell Biochem. 2005; 268: 141-147.

65. Samykutty A, Shetty AV, Dakshinamoorthy G, Bartik MM, Johnson GL, Webb B, et al. Piperine, a bioactive component of pepper spice exerts therapeutic effects on androgen dependent and androgen independent prostate cancer cells. PLoS ONE. 2013; 8: e65889.

66. George K, Thomas NS, Malathi R. Piperine blocks voltage gated $\mathrm{K}^{+}$current and inhibits proliferation in androgen sensitive and insensitive human prostate cancer cell lines. Arch Biochem Biophys. 2019; 667: 36-48.

67. Ouyang DY, Zeng LH, Pan H, Xu LH, Wang Y, Liu KP, et al. Piperine inhibits the proliferation of human prostate cancer cells via induction of cell cycle arrest and autophagy. Food Chem Toxicol. 2013; 60: 424-430.

68. Zeng $Y$, Yang Y. Piperine depresses the migration progression via downregulating the Akt/mTOR/MMP-9 signaling pathway in DU145 cells. Mol Med Rep. 2018; 17: 6363-6370.

69. Fofaria NM, Kim SH, Srivastava SK. Piperine causes G1 phase cell cycle arrest and apoptosis in melanoma cells through checkpoint kinase-1 activation. PloS ONE. 2014; 9: e94298.

70. Pradeep CR, Kuttan G. Effect of piperine on the inhibition of lung metastasis induced B16F-10 melanoma cells in mice. Clin Exp Metastasis. 2002; 19: 703-708.

71. Gunasekaran V, Elangovan K, Devaraj SN. Targeting hepatocellular carcinoma with piperine by radical-mediated mitochondrial pathway of apoptosis: An in vitro and in vivo study. Food Chem Toxicol. 2017; 105: 106-118. 
72. Zhang J, Zhu X, Li H, Li B, Sun L, Xie T, et al. Piperine inhibits proliferation of human osteosarcoma cells via $\mathrm{G} 2 / \mathrm{M}$ phase arrest and metastasis by suppressing MMP-2/-9 expression. Int Immunopharmacol. 2015; 24: 50-58.

73. Qi YB, Yang W, Si M, Nie L. Wnt/ $\beta$-catenin signaling modulates piperine-mediated antitumor effects on human osteosarcoma cells. Mol Med Rep. 2020; 21: 2202-2208.

74. Bezerra DP, Castro FO, Alves AP, Pessoa C, Moraes MO, Silveira ER, et al. In vivo growthinhibition of Sarcoma 180 by piplartine and piperine, two alkaloid amides from Piper. Braz J Med Biol Res. 2006; 39: 801-807.

75. Kasibhatta R, Naidu MU. Influence of piperine on the pharmacokinetics of nevirapine under fasting conditions. Drugs R D. 2007; 8: 383-391.

76. Zadorozhna M, Tataranni T, Mangieri D. Piperine: Role in prevention and progression of cancer. Mol Biol Rep. 2019; 46: 5617-5629.

77. Srinivasan K. Black pepper and its pungent principle-piperine: A review of diverse physiological effects. Crit Rev Food Sci Nutr. 2007; 47: 735-748.

78. Thiel A, Buskens C, Woehrle T, Etheve S, Schoenmakers A, Fehr M, et al. Black pepper constituent piperine: Genotoxicity studies in vitro and in vivo. Food Chem Toxicol. 2014; 66: 350-357.

79. Tak JK, Lee JH, Park JW. Resveratrol and piperine enhance radiosensitivity of tumor cells. BMB Rep. 2012; 45: 242-246.

80. Bastaki M, Aubanel M, Bauter M, Cachet T, Demyttenaere J, Diop MM, et al. Absence of adverse effects following administration of piperine in the diet of Sprague-Dawley rats for 90 days. Food Chem Toxicol. 2018; 120: 213-221.

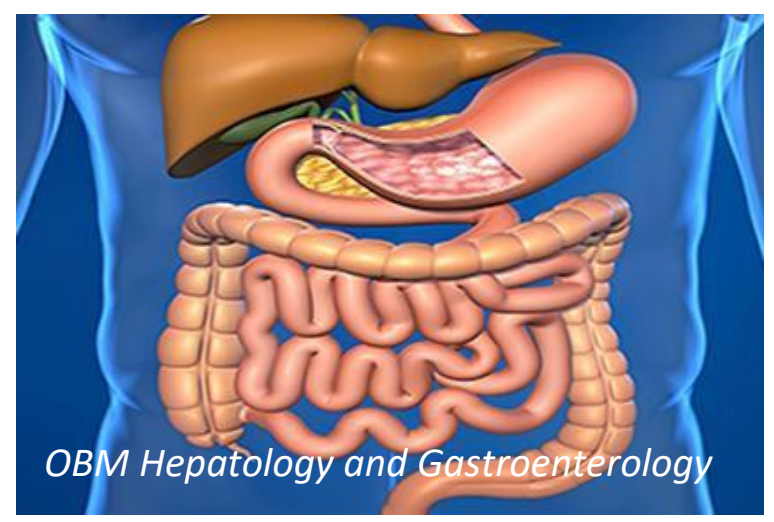

Enjoy OBM Hepatology and Gastroenterology by:

1. Submitting a manuscript

2. Joining in volunteer reviewer bank

3. Joining Editorial Board

4. Guest editing a special issue

For more details, please visit: http://www.lidsen.com/journals/hg 